\title{
Personalized Recommendation approach based on student's performance prediction for E-Learning
}

\author{
Venkatachalapathy. $\mathrm{V}^{1}$, Vijayalakshmi. $\mathrm{V}^{2}$, Roopa. $\mathrm{S}^{3}$ \\ Division of Computer and Information Science ${ }^{1}$, Department of Computer Science and Engineering ${ }^{2,3}$ \\ Professor ${ }^{1}$, Research Scholar ${ }^{2}$, UG Student ${ }^{3}$ \\ Email: vivenan09@gmail.com ${ }^{2}$
}

\begin{abstract}
Personalized E-Learning system should be tailored into student needs, which usually differs even among learners, who attend the same course and have similar technical skills. The proposed system architecture is one where the teaching paths as well as proper layouts are adjusted to groups of students with similar preferences, behavior and historical data. Different types of content are grouped for the same course then it is mapped with the students to provide them better and efficient content. The result will be more effective since we classified students based on all the possible methods. The main motive of the proposed system is to deliver the personalized content of the course material to the particular group of students. It includes parameters such as behavior, historical data and preferences. Firstly by considering all these parameters the similar groups are classified and then the students with similar types are grouped. Then the learning materials are classified and mapped with the similar group of students to provide them better personalized dynamic content.
\end{abstract}

Index Terms- Electronic Learning; Classification; Content Personalization; prediction; Recommendation

\section{INTRODUCTION}

One of the active field of research and experimentation, with remarkable investments from all over the world is E-Learning. It is the process of delivering dynamic, comprehensive and personalized learning content through web. The rapid growth of elearning has changed traditional learning behavior and presented a new situation to both educators (lecturers) and learners (students).

One of the most difficult task for the educators is to guide the students to select suitable learning materials due to more and more learning materials online. Learners find it difficult to make a decision about choosing the learning materials that meets the need to read. Therefore, on the educator's side, educators need an automatic way to get feedback from learners in order to better guide their learning process [1]. On the learner's side, it would be very useful an elearning system could automatically guide the learner's activities and generate and recommend learning materials that would improve the learning.

This study develops a framework for personalized learning recommender systems (PLRS). The framework introduces a personalized recommendation procedure that generates recommendations effectively when applied to online teaching and learning sites. The provided recommendation is expected to have higher accuracy in matching student requirement to learning material, and thus higher acceptance by the students.

Once a learning material database, or a learning activity database, is created and a student's personal information is obtained [2], the PLRS can use a computational analysis model for identifying the student's learning requirement, and matching rules.

\section{LITERATURE SURVEY}

A detailed survey has been taken by reading many early research papers that are based on the different machine learning algorithms and the summary of the survey has been explained effectively in Table 1.

\section{PERSONALIZED RECOMMENDATION SYSTEM}

With the rapid growth of computer and Internet technologies, e-learning can improve the teaching and learning approaches. Learning is a cognitive activity that differs from learner to learner, so the personalized environment is very important in this area. Up to the very recent years, most e-learning systems have not been personalized and many researchers has been attempted to develop personalized e-learning systems to improve online learning. Figure 1 demonstrates the flow diagram of personalized recommendation system. These systems recommend some learning materials to learners regardless of material consistence with the learner interest and learner preferences. Learning systems needs personalized mechanisms to help learners learn more efficiently. The researches use the personalized recommender systems. A recommender system is one that recommends useful and suitable information or suggests strategies that learners might apply to achieve their apparent goals. 


\section{Available online at $w w w . i j r a t . o r g$}

Table 1. Literature Survey.

\begin{tabular}{|c|c|c|c|c|}
\hline Sl.no. & $\begin{array}{c}\text { Title } \\
\end{array}$ & Techniques & Advantages & Limitations \\
\hline 01 & $\begin{array}{l}\text { A Framework for } \\
\text { Recommendation of } \\
\text { courses in E-learning } \\
\text { System [3] }\end{array}$ & $\begin{array}{l}\text { Association Rule } \\
\text { mining }\end{array}$ & $\begin{array}{l}\text { The students are grouped } \\
\text { effectively based on } \\
\text { Apriori algorithm of } \\
\text { Association rule mining }\end{array}$ & $\begin{array}{l}\text { Only by using the behavior } \\
\text { data of the students they are } \\
\text { grouped into similar types. } \\
\text { So it is not much effective. }\end{array}$ \\
\hline 02 & $\begin{array}{l}\text { An Architecture for } \\
\text { Recommendation of } \\
\text { Courses in E-learning } \\
\text { System [4] }\end{array}$ & $\begin{array}{l}\text { Clustering } \\
\text { Technique: } \\
\text { K-Means and Apriori } \\
\text { algorithm }\end{array}$ & $\begin{array}{l}\text { The students are grouped } \\
\text { effectively by using } \\
\text { Clustering technique and } \\
\text { based on their profiles } \\
\text { they are grouped using } \\
\text { Apriori algorithm }\end{array}$ & $\begin{array}{l}\text { It is little difficult since it } \\
\text { uses two different algorithms } \\
\text { and to map between the } \\
\text { content and the similar group } \\
\text { of students. }\end{array}$ \\
\hline 03 & $\begin{array}{l}\text { An intelligent } \\
\text { E-learning system based } \\
\text { on learner profiling and } \\
\text { learning resources } \\
\text { adaptation [5] }\end{array}$ & $\begin{array}{l}\text { Electronic } \\
\text { Questionnaire }\end{array}$ & $\begin{array}{l}\text { It groups students based } \\
\text { on the certain test with the } \\
\text { help of marks. This } \\
\text { technique is efficient to } \\
\text { classify students. }\end{array}$ & $\begin{array}{l}\text { It is fully based on students' } \\
\text { performance on certain test } \\
\text { so it is not much effective. }\end{array}$ \\
\hline 04 & $\begin{array}{l}\text { Discovering student } \\
\text { preferences } \\
\text { E-learning [6] }\end{array}$ & Decision model & $\begin{array}{l}\text { Based on the preference } \\
\text { of students they are } \\
\text { classified into similar } \\
\text { groups more effectively. }\end{array}$ & $\begin{array}{l}\text { It is used to classify only } \\
\text { based on preference it does } \\
\text { not consider about the } \\
\text { background details of the } \\
\text { student. }\end{array}$ \\
\hline 05 & $\begin{array}{l}\text { Cluster analysis in } \\
\text { personalized } \\
\text { E-learning systems [7] }\end{array}$ & $\begin{array}{l}\text { Clustering technique } \\
\text { and two phase } \\
\text { hierarchical } \\
\text { technique }\end{array}$ & $\begin{array}{l}\text { It groups students and } \\
\text { provides different content } \\
\text { among learners attending } \\
\text { same courses. }\end{array}$ & $\begin{array}{l}\text { Even though they provide } \\
\text { dynamic content it is not } \\
\text { feasible to provide learning } \\
\text { materials more effectively }\end{array}$ \\
\hline 06 & $\begin{array}{l}\text { Discovering relevant } \\
\text { preferences in a } \\
\text { personalized } \\
\text { recommender system } \\
\text { using machine learning } \\
\text { techniques [8] }\end{array}$ & $\begin{array}{l}\text { Meta evaluation } \\
\text { methodology and } \\
\text { Decision trees \& } \\
\text { Attribute selection }\end{array}$ & $\begin{array}{l}\text { The recommendation of } \\
\text { learning material is } \\
\text { provided using ML } \\
\text { techniques to identify } \\
\text { user's needs and } \\
\text { suggested information }\end{array}$ & $\begin{array}{l}\text { It uses ML technique which } \\
\text { is not effective to group } \\
\text { students to provide them } \\
\text { better learning materials }\end{array}$ \\
\hline 07 & $\begin{array}{l}\text { A personalized } \\
\text { E-learning material } \\
\text { recommender system [9] }\end{array}$ & $\begin{array}{l}\text { Multi attribute } \\
\text { evaluation and Fuzzy } \\
\text { matching technology }\end{array}$ & $\begin{array}{l}\text { It is one of the framework } \\
\text { that is build based on } \\
\text { learning materials based } \\
\text { on the students' needs that } \\
\text { provides more effective } \\
\text { content }\end{array}$ & $\begin{array}{l}\text { It uses a technique which is } \\
\text { used to justify student need } \\
\text { and to match suitable } \\
\text { learning materials which is } \\
\text { not much effective to provide } \\
\text { a personalized content }\end{array}$ \\
\hline 08 & $\begin{array}{l}\text { Recommender system for } \\
\text { predicting student } \\
\text { performance }[10]\end{array}$ & Regression method & $\begin{array}{l}\text { Based on the result of the } \\
\text { prediction of the students' } \\
\text { performance the } \\
\text { recommendation of the } \\
\text { learning material is } \\
\text { provided }\end{array}$ & $\begin{array}{l}\text { It uses matrix factorization } \\
\text { which is a cold start problem } \\
\text { and the logistic or linear } \\
\text { regression is not effective to } \\
\text { classify the students based on } \\
\text { the performance }\end{array}$ \\
\hline 09 & $\begin{array}{l}\text { Combination of machine } \\
\text { learning algorithms for } \\
\text { recommendation of } \\
\text { courses in E-Learning } \\
\text { System based on } \\
\text { historical data [11] }\end{array}$ & $\begin{array}{l}\text { Clustering and } \\
\text { Association rule } \\
\text { mining algorithm }\end{array}$ & $\begin{array}{l}\text { The Recommendation of } \\
\text { content is based on } \\
\text { historical data and } \\
\text { behavior by using Moodle } \\
\text { and Weka tool }\end{array}$ & $\begin{array}{l}\text { Without prediction the } \\
\text { personalization process is not } \\
\text { efficient even though based } \\
\text { on two different parameter it } \\
\text { is not categorized based on } \\
\text { prediction }\end{array}$ \\
\hline 10 & $\begin{array}{l}\text { Automatic } \\
\text { recommendations for } \\
\text { E-learning personalization } \\
\text { based on web usage } \\
\text { mining techniques and } \\
\text { information retrieval [12] }\end{array}$ & $\begin{array}{l}\text { Content based } \\
\text { filtering and } \\
\text { collaborative filtering } \\
\text { approaches }\end{array}$ & $\begin{array}{l}\text { It is based on the } \\
\text { navigation history (i.e.,) } \\
\text { fully based on the web } \\
\text { usage without explicit } \\
\text { feedback }\end{array}$ & $\begin{array}{l}\text { It is based on the oldest } \\
\text { approaches which is not } \\
\text { much effective nowadays }\end{array}$ \\
\hline
\end{tabular}




\section{Available online at www.ijrat.org}

It helps both the learner and the learning system. The learning systems recommends suitable learning materials. In other hand, they help the learner to spend less time in contrast to before. In general, to provide personalization in e-learning systems learners' knowledge and learning material knowledge are necessary [13]. Nowadays, most recommendation and personalized systems consider learner preferences, interests and learner knowledge. Due to this section, we can conclude that e-learning recommendation systems are different from other domains.

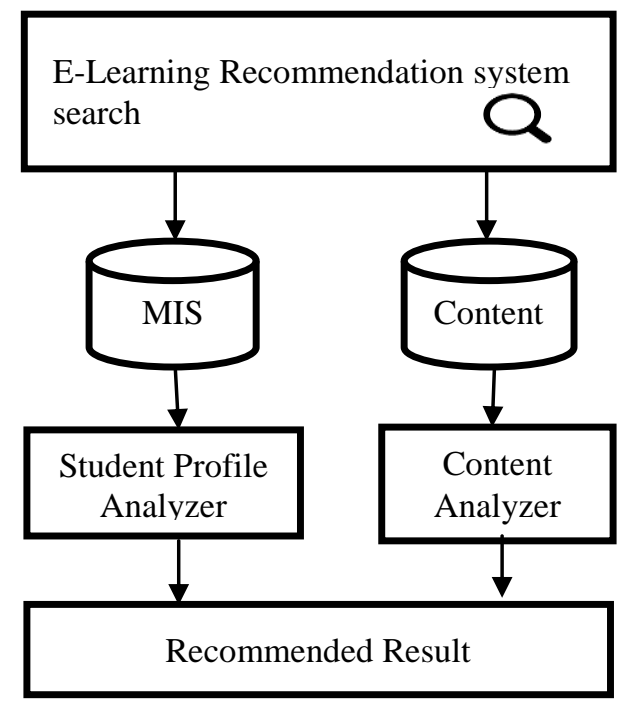

Fig. 1. Personalized Recommendation Process

This study proposes a personalized group-based recommendation system for E-Learning application. In the profiling process, students are categorized into three groups: Beginner, Intermediate and Master. This is derived from their academic records and learning behaviors. The students' profiles are automatically updated based on their learning behaviors in the proposed system. Moreover, when the system detects any change in the academic records, it also fetches the updated information and it dynamically updates the user's profile. For each type of student group, the students' implicit feedbacks such as link selections, search activities and log histories are analyzed and then stored in the local server. By consistently comparing this information with other students who carry similar profiles, a dynamic link recommendation outcome can be achieved. The students' profiles and content ranking lists are updated dynamically. This is based on the changes noted in their academic records, learning behaviors and other related contextual records.

\subsection{Student profile classification}

The main aim of this module is to construct and maintain the profile of each and every learner. It allows the system to understand different learning needs and capabilities of each and every individual learner. To accomplish this, the module has two functional components: Academic Record Analyzer and Behavioral Activity Analyzer. Learner profile is the key component of any e-learning system. Therefore, this study uses the most well-known user profiling model to classify the learner's profile. It considers the following elements: Academic, Behavioral and Contextual record. The main usage of the academic record is to measure the individual student's past and present academic performance. This information is derived from the Student MIS. The system also observes the student's learning behavioral activities through his/her browsing histories and session data [14]. The main goal is to assess the interest level and the activeness of the student towards learning while using E-learning application. If any change is noted in the learner's academic information or the behavioral record then his/her profile will be automatically updated. The system also identifies coherent contexts by tracking any changes exhibited in his/her academic and behavioral records for a certain time span. The time span may range crossing months of data as contextual information begins to correspond to the dynamic profile need. The Figure 2 depicts the process involved in Student profile system.

\subsubsection{Academic Record Analyzer}

The Academic Record Analyzer module has the main responsible of identifying the signed-in learners by retrieving their profiles from the Student MIS. It retrieves learners' previous and current academic information and then stores the information in the local server for further processing. Subsequently, it calculates the standard Test Scores extracted from the academic records for each learner. The Test Score is one form of standardized test statistics that transform individual raw scores into standardized forms of scores for ease of comparison. Furthermore, the Test Score also reduces natural variations. By averaging the calculated standard Test Scores, an average score is achieved for each student. This helps to classify the students' profiles. In this study, we define it as Knowledge Level Value (KLV). Typeset subsubheadings in medium face and capitalize the first letter of the first word only. 


\section{Available online at www.ijrat.org}

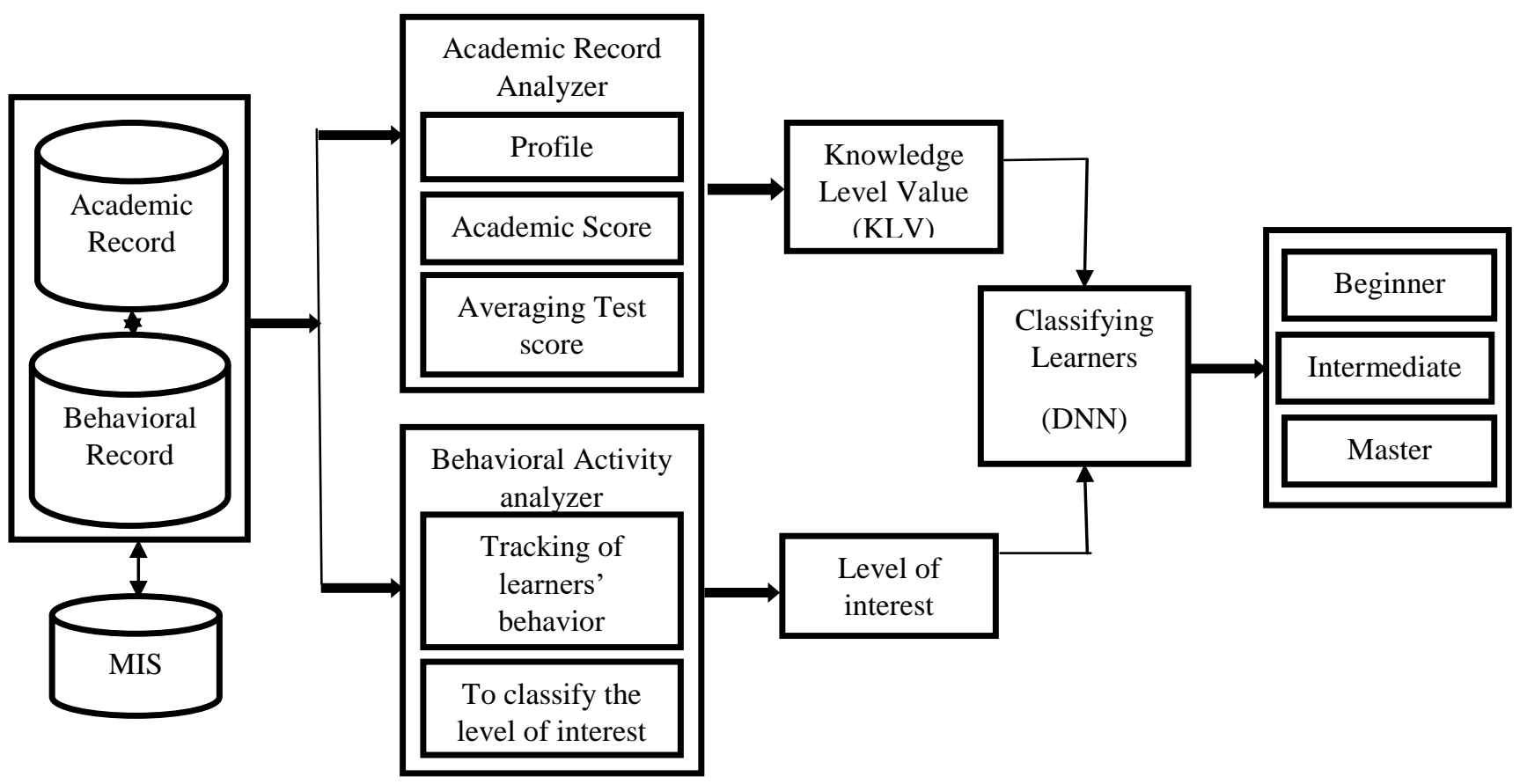

Fig. 2. Student profiling model

\subsubsection{Behavioral Activity Analyzer}

The Behavioral Activity Analyzer module is mainly responsible for continuously monitoring and capturing the learners' learning behaviors. The learning activities of each and every learner is recorded and stored individually as extracted from their browsing histories and session logs. All information is stored inside the local server. The data captured comprises of number of times they login, the number of search per login, links clicked, the selected documents, page names, page sizes, average scrolls, the issued queries, and time spent. Subsequent to that, the activities that are stored are analyzed to classify the learners' level of interest towards learning while they search for the relevant learning materials. Through this the learners' behavioral activity can be easily analyzed. The learners' learning behaviors to be classified into three different levels: Low, Medium and High. This classification is mainly regarding the learners' level of interest towards learning.

\subsubsection{Student Profile Classification}

From the earlier sections, the learner's knowledge Level Value (KLV) and level of interest are obtained. These outputs require further processing to classify every learner's profile. The Figure 2 explains the process of classification of learners' profile effectively. The classification is based according to their academic performance (knowledge level value) and learning behaviors (level of interest towards learning). In order to achieve this, the Deep Neural Network (DNN) algorithm is applied. This algorithm is used effectively in Recommendation system to extract meaningful features for a latent factor model for content-based recommendations.

The Deep Neural Network has been applied for learning user preferences from multiple domains. This model uses a hybrid collaborative and content-based approach and enhances recommendations in multiple task. This enables the learners to be effectively classified into three groups (Beginner, Intermediate and Master) [15]. The Figure 3 depicts the decision tree model which is translated into the following rules by using the student's Knowledge Level Value (KLV) and interest level:

1) Students with KLV higher than 85 will be assigned a Master Class.

2) Students with KLV less than 55 will be assigned a Beginner Class.

3) Students with $\mathrm{KLV}<=85,>=55$ are classified based on the following:

- If his/her interest level is Low, then he/she will be assigned a Beginner Class. 


\section{E-ISSN: 2321-9637 \\ Available online at www.ijrat.org}

- If his/her interest level is Medium, then he/she will be assigned an Intermediate class.

- If his/her interest level is High, then he/she will be assigned a Master Class.

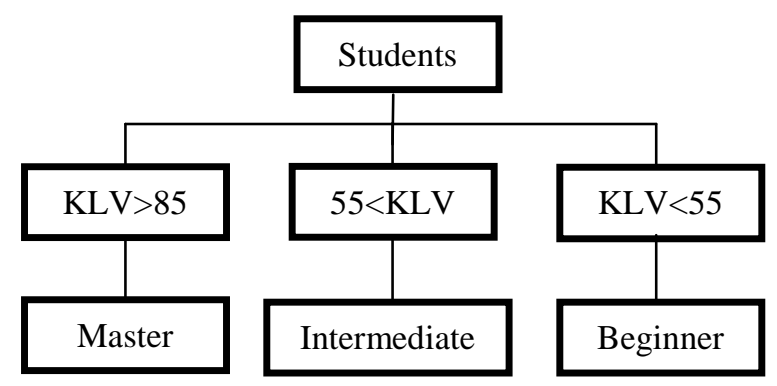

Fig. 3. Decision tree for Student Profile Classification

\subsection{Content Re-ranking}

The personalized features can return different learning materials for dissimilar individuals. Alternatively, it matches the content outcomes in a different way according to the learner's intent based on the learner's information needs and preferences. However, it is very challenging to collect learner's data which should be rich enough that can understand the user's precise needs and preferences. The best way to address this challenging task is by combining related data gathered from other individuals with similar profiles when building personalization features. It is established by assigning higher weights to pages that are apposite with the predominance of the members of the group. This is achieved by harmonizing with every group member's document term frequencies and behavioral data. This method effectively improve the value of collaborative content materials. This can be performed by using personalization with shared interests. In the collaborative filtering technique, the recommender system suggests items depending on how identical users desire the item. It endeavors to uncover others with similar or related concerns. However, the matches are constructed based solely on queries or on suggestions or community connectedness not rankings.

On the other hand, our proposed personalized group-based recommendation approach is able to use the advantage of the K-Means algorithm to discover different learning content within the homogeneous group of learning materials in an educational institution environment. This process helps to strengthen the approach in delivering more accurate personalized recommendations within the e-learning domain. The motivation behind using this technique is to improve the ranking of the learning materials thereby making it more relevant according to student's profile. To achieve this, the K-Means algorithm performs group assessments on different learning materials. Specific groups are given priorities to certain contents based on the content that is useful for group members of similar profiles. To execute this type of classification based on learning materials, few steps are involved. First, a personalization score is calculated for every learning material for every member of a group. Next, the score will be calculated as the grand total of the personalization scores of every member of the group. Subsequently, a weighted combination of the score and the learning materials original rank is considered. Through this the learning materials can be classified effectively by using $\mathrm{K}$ Means algorithm.

\section{RESULT AND DISCUSSION}

Many e-learning applications have been extensively used by the students for educational purposes, they deliver similar contents regardless of students' profiles. This is not much beneficial to the students because the same contents may not meet the requirements of every student. In this study, a personalized group based recommendation approach for eLearning application was proposed. We designed an adaptive system that comprises dynamic profiling and content re-ranking mechanism that helps students in finding learning materials based on their academic records and learning behaviors. The proposed system has the ability to recommend and prioritize the top five most suitable links to students depending on their personal profiles. It gained a significantly better learning as compared to the earlier system.

This finding implies that the personalized groupbased recommendation system is helpful in improving the effectiveness of the students' learning performance and it suggests that the personalized group-based recommendation approach was able to make the process of searching for learning materials more effective. To provide a personalized learning material, the recommender system needs to access users' personal profiles, description of user interest and user behavior. However, it is challenging for any recommender system to collect users' data, thus more innovative approaches need to be considered. 


\section{Available online at www.ijrat.org}

In this study, the proposed system employed in the educational institutional environment where student data can be obtained from the Students' Management Information System. This therefore enriches the data of the students to construct rich user profile. By utilizing a rich user profile and by identifying students with similar learning potential and attitude, the elearning application can provide a more personalized recommendation of the learning materials. Therefore, future work should consider delivering a seamless personalized recommended learning materials to the learners. Additionally, the possibility of incorporating students' social identities from their social networks for richer students' profiles and more desirable recommendation outcomes would also be an appealing topic to explore.

\section{CONCLUSION}

In proposed intelligent e-learning system, the personalized teaching paths as well as information content organization are adjusted to student groups of different requirements. This technique enables to find student groups according to their individual learning style, usability preferences and behavior of all the students who differ significantly from other students are indicated. In this we concerned the parameters such as student's preference, knowledge and historical data to improve their learning performance. We propose a personalized e-learning system which takes the dynamic learner's personality into account. In this system appropriate teaching strategy are used to achieve the learning. The results indicate that placing the learner beside an appropriate teaching style matching with learner's preference lead to improvement and make the virtual learning environment more enjoyable. This model is very suitable in e-learning systems that need to "filter" the great volumes of information available, so that their users can make a better use of it.

\section{REFERENCES}

[1] Shishehchi, Saman, et al. "Review of personalized recommendation techniques for learners in elearning systems." Semantic Technology and Information Retrieval (STAIR), 2011 International Conference on. IEEE, 2011.

[2] Chen, Chih-Ming, Hahn-Ming Lee, and Ya-Hui Chen. "Personalized e-learning system using item response theory." Computers \& Education 44.3 (2005): 237-255.
[3] Aher, Sunita B., and L. M. R. J. Lobo. "A Framework for Recommendation of courses in Elearning System." International Journal of Computer Applications 35.4 (2011): 21-28.

[4] Rawat, Bhupesh, and S. Dwivedi. "An Architecture for Recommendation of Courses in Elearning System." IJ Information Technology and Computer Science 4 (2017): 39-47.

[5] Tzouveli, Paraskevi, Phivos Mylonas, and Stefanos Kollias. "An intelligent e-learning system based on learner profiling and learning resources adaptation." Computers \& Education51.1 (2008): 224-238.

[6] Carmona, Cristina, Gladys Castillo, and Eva Millán. "Discovering student preferences in elearning." Proceedings of the international workshop on applying data mining in elearning. 2007.

[7] Zakrzewska, Danuta. "Cluster analysis in personalized e-learning systems." Intelligent Systems for Knowledge Management. Springer, Berlin, Heidelberg, 2009. 229-250.

[8] Bellogín, Alejandro, et al. "Discovering relevant preferences in a personalised recommender system using machine learning techniques." Proceedings of the ECML-PKDD 2008 Workshop on Preference Learning. 2008.

[9] Lu, Jie. "A personalized e-learning material recommender system." International Conference on Information Technology and Applications. Macquarie Scientific Publishing, 2004.

[10] Thai-Nghe, Nguyen, et al. "Recommender system for predicting student performance." Procedia Computer Science1.2 (2010): 2811-2819.

[11] Aher, Sunita B., and L. M. R. J. Lobo. "Combination of machine learning algorithms for recommendation of courses in E-Learning System based on historical data." KnowledgeBased Systems 51 (2013): 1-14.

[12] Khribi, Mohamed Koutheaïr, Mohamed Jemni, and Olfa Nasraoui. "Automatic recommendations for e-learning personalization based on web usage mining techniques and information retrieval." Advanced Learning Technologies, 2008. ICALT'08. Eighth IEEE International Conference on. IEEE, 2008.

[13] Huang, Mu-Jung, Hwa-Shan Huang, and Mu-Yen Chen. "Constructing a personalized e-learning system based on genetic algorithm and case-based reasoning approach." Expert Systems with Applications 33.3 (2007): 551-564.

[14] Essaid El Bachari, El Hassan Abelwahed, and Mohammed El Adnani. "E-LEARNING PERSONALIZATION BASED ON DYNAMIC LEARNERS'PREFERENCE." (2011).

[15] Rahman, Mohammad Mustaneer, and Nor Aniza Abdullah. "A Personalized Group-Based Recommendation Approach for Web Search in ELearning." IEEE Access 6 (2018): 34166-3417. 